\title{
The reform of teaching mode for algorithm courses in computer specialty
}

\author{
Chunyan Zhang ${ }^{1, a}$, Guorong Chen ${ }^{2, b}$ \\ ${ }^{1}$ Nanchang institute of science \& technology, China \\ ${ }^{2}$ Software College of Jiangxi Ahead University, China
}

\begin{abstract}
Keywords: computer specialty, algorithm course, teaching reform, network teaching platform
\end{abstract}
\begin{abstract}
Aiming at the problems existed in the teaching process of algorithm courses in computer specialty, this paper combined the current teaching philosophy with the author's own teaching practice, discussed a kind of teaching reform mode for algorithm courses in computer specialty under the assistance of network teaching platform, in order to stimulate the learning interest and enthusiasm of students in the process of education teaching, to enhance the teaching effect, to improve the students' autonomous learning ability, innovation and practical ability.

In the process of teaching in computer specialty, the algorithm course plays a decisive role, especially has an irreplaceable position for training students' ability to use computer to solve practical problems in production. The training program in computer specialty involves many algorithm courses, not only have professional basic courses, such as data structure, algorithm analysis and calculation method, but also have some professional elective courses, such as digital image processing and computer graphics. In addition, some colleges and universities also offer the elective courses such as artificial intelligence and pattern recognition for the senior undergraduate students in computer specialty. These algorithm courses in computer specialty, not only require students to have solid mathematical foundation knowledge and strong programming ability, but also require students to have strong ability of independent learning and innovation. Traditional teaching mode of "teachers teach in classroom, students verify by experiment" has already can not adapt to the current teaching requirements in colleges and universities, it is difficult to bear the responsibility of higher education to cultivate innovative talents. Therefore, the teaching reform of algorithm course in computer specialty is an important task that the current universities faced. At present, the new teaching mode represented by MOOC brought great impact and influence on the traditional teaching mode, at the same time, but also provided a new way for the traditional teaching reform. In the current environment, how to draw lessons from these new types of teaching mode, reforming and innovating the teaching mode of algorithm courses in computer specialty is a urgent problem that computer specialty education faced in colleges and universities. This paper combined these new teaching modes with teaching practice, discussed the teaching mode reform of algorithm course in computer specialty, in order to stimulate students' learning interest and enthusiasm in the process of teaching, to guide students to autonomous learning, so as to improve the teaching effects of algorithm courses in computer specialty, to cultivate students' innovation spirit and practice ability.
\end{abstract}

\section{The present teaching situation of algorithm courses in computer specialty}

(1) From the teaching contents, the demand of algorithm courses in computer specialty for students is higher, excepts the programming language, is also involved many mathematical basic courses, including higher mathematics, linear algebra, mathematical statistics and so on. Faced with such a complex and diverse course content, within the limited class hour, the teacher is very difficult to speak the knowledge thoroughly, and the students are difficult to understand and master knowledge in time, and are difficult to build a complete knowledge system. In addition, most of the key points in the syllabus requirements are old, out of touch with scientific research and actual production, students can not find the fun of learning. In the process of actual teaching, the teaching effect of algorithm courses in computer specialty is not ideal, the initiative and enthusiasm of learning for students is low.

(2) From the theoretical teaching, at present, teachers usually adopt the traditional teaching mode 
of "teachers speak, students listen" in the classroom teaching, lack of communication and exchanges between teachers and students, students completely in a state of passive to accept knowledge, unable to get experience, learning interest, enthusiasm and initiative is not high. In addition, this single teaching mode does not consider the individual differences of students, thus there is no way to teach students in accordance with their aptitude.

(3) From the experiment teaching, in the process of current teaching, the experimental class compared with the theory class is less, and most of them are confirmatory experiments, lack of innovation, it is difficult to bring the interest of students in experiment. Although the theoretical of algorithm course in computer specialty is strong, but still need a lot of experiment contents. Only by constantly test and summary to let students understand the essence of all kinds of algorithms, otherwise the students can't experience the real use of all kinds of algorithms, not to mention, to stimulate the students' interest in learning. In addition, due to the limited class, the teacher can't timely grasp and evaluate students' experiment result, the students also can't grasp their own learning situation in a timely manner.

(4) From the subjective view of teaching and learning, there is lack of communication and interaction between teachers and students. Teaching process is accomplished by the teacher and students, at present, the teaching mode in colleges and universities is doomed to the communication between teacher and the students mostly concentrated in the classroom, the heavy teaching tasks make the teacher can't answer the students one by one within the limited class hour. This will cause that students encountered difficult problems in their autonomous learning and experiment after class, unable to timely communicate with their teachers.

(5) From the course assessment and evaluation mode, although the teachers can examine and evaluate the student's classroom study situation through combining student's usual result, practice result and examination (or test) result, but unable to track and manage the extracurricular learning situation of students, lack of corresponding evaluation method for each student's extracurricular autonomous learning time and effect. At present, the teachers can only according to the students' performance of homework, classroom questioning and discussion to evaluate students' learning situation, fail to realize the tracking and investigation of real learning process for students, for student's actual learning situation assessment is not comprehensive and objective.

\section{The teaching mode reform of algorithm courses in computer specialty}

Aiming at the problems existed in the teaching process of algorithm courses in computer specialty, this paper discussed a kind of teaching reform mode for algorithm courses in computer specialty under the assistance of network teaching platform, in order to optimize the integration of algorithm courses in computer specialty, to build online teaching and experiment platform, to promote the autonomous learning for students, to meet the requirements to interact and discuss the questions and answers between teachers and students, to supervise and manage the learning of students comprehensively and objectively. Specific implementation ideas as follows:

(1) optimizing and integrating various courses, to establish the curriculum group of algorithm courses in computer specialty. For algorithm courses in computer specialty, there are some in common between them, that is all based on mathematics, need to use programming technique to realize, and most of the courses are related, exists certain support relationship betwee20n before and after. In the process of algorithm courses curriculum group construction in computer specialty need to emphasize the connection between the courses, weaken the independence of the courses, strengthen the integration and cross of curriculum resources. The construction of this integrated curriculum group can integrate scattered knowledge in the course to a great extent, optimize the teaching structure, remove the useless knowledge, ensure the practicability of knowledge points, fully train students' ability of various aspects in the teaching, make students have a complete understanding for algorithm courses.

(2) Design and construct the online teaching platform of algorithm course in computer specialty, to achieve the teaching philosophy of "teachers speak less and earnestly, strengthen students' autonomous learning ability". The theory of algorithm course in computer specialty is strong, and 
the practicality is more important. In order to combine the theory and practice of knowledge, within the limited class hour, teachers can't do everything to the knowledge for multifarious knowledge point, can only speak less and earnestly, this needs to strengthen the ability of autonomous learning for students. The construction of online teaching platform overturned the traditional classroom, to expand the teaching activities from class to extracurricular, make the students can according to their own needs to learn, truly achieved the advanced teaching ideas of "take the students as the center". According to the characteristics of the algorithm course in computer specialty, this platform need to transfer the teaching content and experimental demonstration from the class to the platform on the basis of the curriculum group construction, for students to learn. At the same time, this platform must be able to provide the corresponding virtual experiment environment and the directions for use, in order to offer students online experiment, and feedback the experimental results timely.

(3) Perfect the theory and experiment teaching resources, to create a multidimensional hierarchy of online learning environment. In the process of online teaching platform construction for algorithms course for computer specialty, the teachers need to according to the knowledge system of the curriculum group, sort out the key points and difficulties of knowledge points, in order to further perfect the theoretical teaching resources. At the same time, teachers need to optimize the experiment teaching contents, carefully design the experiment outline, according to the needs to design three kinds of experimental design routine libraries, and load the questions and answers on online teaching platform respectively. The first category is mainly the verification experiment, mainly for student self-testing, examining the mastery of individual knowledge for students, students can conduct self assessment of the autonomous learning situation after the completion, if possible, can design the subject as "go off" mode, in order to increase the fun of autonomous learning. The second type is mainly designed experiments, is mainly used to comprehensively analyze and test students' ability of knowledge utilizing, students can submit online after completed, for teachers to correct online. Third type is mainly comprehensive experiments, subjects mainly come from teachers' scientific research project and the frontier areas technology, the purpose is to develop and test the ability to use knowledge to solve practical problems in production and the team consciousness of collaboration, the students can be divided into groups when they finish the experiment.

(4) Build online tutoring answering and exchange sharing platform, to realize the deep interaction between teachers and students. Through the establishment of communication platform, teachers and students can use the Internet to communicate and discuss, break through the space and time limit of traditional classroom, conducive to the deep interaction between teachers and students. Mainly includes two aspects: one is the tutoring online answering questions, students can choose the teacher to ask questions according to their own needs, the asked teacher will see the problem after the launch which the students submitted, and give solutions, in addition, teachers and students can also ask questions for group discussion. Another is online sharing, teachers upload the teaching materials and solutions in the form of post, to assist classroom teaching, students can also publish their own thoughts, questions and data to the platform, so as to achieve the aim of communication sharing, to improve students' participation in the construction of teaching platform for algorithm courses in computer specialty.

(5) Build management and tracking platform, to establish perfect effective assessment and evaluation system. In the process of teaching platform construction for algorithm courses in computer specialty, platform need to be able to count the basic information, such as the number of online learning, time and test scores, to manage, track and count the students' autonomous learning situation. According to statistics, the platform needs to be able to analyze the statistical data, and to establish the relationship between the students' participation in question answering, interaction, and the effect of learning and the ability of autonomous learning, in order to induct and summary some basic rules and methods of students' autonomous learning ability. At the same time, according to the analysis and statistics, the platform need to be able to evaluate students' autonomous learning situation, in order to make the evaluation more real and effective, and more maneuverable. In addition, the evaluation should be comprehensively and objectively reflect the reality of the students 
learning situation, in order to conduct a comprehensive investigation on the students' learning attitude, learning ability, communication, cooperation ability and innovation ability, etc.

\section{Conclusion}

Aiming at the problems existed in the teaching process of algorithm courses in computer specialty, this paper combined the current teaching philosophy with the author's own teaching practice, discussed a kind of teaching reform mode for algorithm courses in computer specialty under the assistance of network teaching platform from five aspects, including curriculum group construction, teaching platform construction, teaching resources, interactive platform and evaluation system, in order to enhance the teaching effect, to improve the students' autonomous learning ability, innovation and practical ability.

\section{References}

[1] Lanjun Wan, Haixia Luo. The exploration on the reform of Java course teaching faced to MOOC[J]. Computer knowledge and technology, academic exchanges, 2014 (10 x).

[2] Dengfeng Liu, Ningning Qin, Baoguo Xu. Thinking on the network online experiment platform construction mode of experiment course for computer composition principle [J]. Journal of education teaching BBS, 2016 (16).

[3] Zhiyong Xiao, Yunhao Yuan, Jinlong Yang. The exploration on teaching reform of computer specialized course: take "the processing techniques of digital image" for example [J]. Journal of education modernization, 2015, 12.

[4] Li Yingmei Li, Weining Xia, Jinfeng Ding. The curriculum group construction of Java programming language[J]. Journal of computer education, 2012, 7. 